This article was downloaded by: [Ewen Speed]

On: 27 May 2015, At: 00:32

Publisher: Routledge

Informa Ltd Registered in England and Wales Registered Number: 1072954 Registered office: Mortimer House, 37-41 Mortimer Street, London W1T 3JH, UK

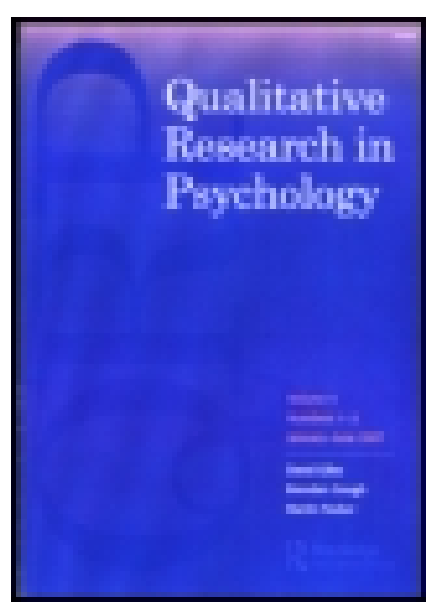

CrossMark

Click for updates

\title{
Qualitative Research in Psychology
}

Publication details, including instructions for authors and subscription information: http://www.tandfonline.com/loi/uqrp20

\section{"Because You're Worth It": A Discourse Analysis of the Gendered Rhetoric of the ADHD Woman}

\author{
Helen Winter ${ }^{a}$, Joanna Moncrieff ${ }^{b} \&$ Ewen Speed $^{c}$ \\ a Kids Company, London, UK. \\ ${ }^{\mathrm{b}}$ University College London, London, UK \\ c University of Essex, Colchester, UK \\ Accepted author version posted online: 26 May 2015.
}

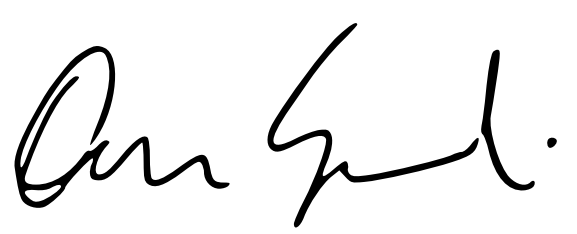

To cite this article: Helen Winter, Joanna Moncrieff \& Ewen Speed (2015): “Because You're Worth It”: A Discourse Analysis of the Gendered Rhetoric of the ADHD Woman, Qualitative Research in Psychology

To link to this article: http://dx.doi.org/10.1080/14780887.2015.1050748

Disclaimer: This is a version of an unedited manuscript that has been accepted for publication. As a service to authors and researchers we are providing this version of the accepted manuscript (AM). Copyediting, typesetting, and review of the resulting proof will be undertaken on this manuscript before final publication of the Version of Record (VoR). During production and pre-press, errors may be discovered which could affect the content, and all legal disclaimers that apply to the journal relate to this version also.

\section{PLEASE SCROLL DOWN FOR ARTICLE}

Taylor \& Francis makes every effort to ensure the accuracy of all the information (the "Content") contained in the publications on our platform. However, Taylor \& Francis, our agents, and our licensors make no representations or warranties whatsoever as to the accuracy, completeness, or suitability for any purpose of the Content. Any opinions and views expressed in this publication are the opinions and views of the authors, and are not the views of or endorsed by Taylor \& Francis. The accuracy of the Content should not be relied upon and should be independently verified with primary sources of information. Taylor and Francis shall not be liable for any losses, actions, claims, proceedings, demands, costs, expenses, damages, and other liabilities whatsoever or howsoever caused arising directly or indirectly in connection with, in relation to or arising out of the use of the Content.

This article may be used for research, teaching, and private study purposes. Any substantial or systematic reproduction, redistribution, reselling, loan, sub-licensing, systematic supply, or distribution in any form to anyone is expressly forbidden. Terms \& Conditions of access and use can be found at http:// www.tandfonline.com/page/terms-and-conditions 


\section{H. Winter et al.}

\section{Gendered Rhetoric of the ADHD WomanRight running head OK?}

\section{“Because You're Worth It": A Discourse Analysis of the Gendered Rhetoric of the ADHD}

Woman

Helen Winter ${ }^{1}$, Joanna Moncrieff ${ }^{2}$ and Ewen Speed $^{3}$

${ }^{1}$ Kids Company, London, UK

${ }^{2}$ University College London, London, UK

${ }^{3}$ University of Essex, Colchester, UK

Correspondence: Joanna Moncrieff, Division of Psychiatry, University College London, Charles Bell House, 57-63 Riding House Street, London W1W 7EJ, UK. E-mail: j.moncrieff@ucl.ac.uk Drawing on the traditions of discursive psychology and critical discourse analysis this study examined the presentation of attention deficit hyperactivity disorder (ADHD) in women in a sample of the most commonly identified online YouTube videos on this topic. The video material selected represented a combination of first-person testimonies from the "sufferer" and the sharing of "expertise" by "professionals." Analysis involved the identification of common rhetorical devices and evaluation of the role of these devices in conveying various key meanings or themes. The categories generated by this method told a story of the construction of an "ADHD product" presented to women by other women, and unproblematically positioned within the biomedical discourse. Stimulant medication was endorsed for its ability to improve performance 
at work and in the domestic sphere. Women sufferers in the videos appear as "active consumers" promoting the ADHD diagnosis for its ability to enable them to fulfil the "superwoman" ideal. The medicalisation of underperformance witnessed in the videos is discussed in relation to literature on modern-day "discourses of femininity."

Keywords: attention deficit hyperactivity disorder; discourse analysis; feminist theory; Internet; medicalization; stimulant medication

\section{Introduction}

Attention-deficit/hyperactivity disorder (ADHD; also known as attention deficit disorder, or ADD) is a diagnosis that divides opinion and ignites debate. Some assert its existence as a legitimate medical disorder (e.g., Asherson 2013); others regard it as a cultural construction (e.g., Timimi \& Leo 2009). Prevalence rates continue to increase among child and adolescent populations (Getahun et al. 2013). Evidence of increasing prescriptions of stimulant drugs to adults suggests the adult ADHD diagnosis is also gaining in popularity (Castle et al. 2007) and the incorporation of more adult-inclusive criteria into the Diagnostic and Statistical Manual of Mental Disorders (DSM-5) sets the stage for this trend to escalate (Whitely 2011). <AQ: Whitely is not listed in References>

Considering data from children diagnosed with ADHD, it may be assumed that the adult demographic would be predominantly male. However, most studies do not support this prediction. A meta-analysis of prevalence studies found that five out of eight studies found a female preponderance in the diagnosis, with women comprising up to $<\mathrm{AQ}$ : these statistics as 
presented are confusing. Do you mean women represent up to $86 \%$ and adults $83 \%$ ? $>86 \%$ and $83 \%$ of adults with the diagnosis in some countries (Simon et al. 2009). Moreover, data from the United States suggests women show the highest growth rate in ADHD medication use of any demographic group (Castle et al. 2007).

Some authors attribute this demographic shift to women having gone undiagnosed in childhood (Simon et al. 2009, p. 209). This hypothesis is informed by the assumption that males display ADHD through "externalising" behaviour whereas females show "internalising" behaviour. Therefore, ADHD may only become obviously symptomatic with the introduction of adult stressors such as family, work, and study (Bren 2004).

An alternative feminist critique suggests that adult $\mathrm{ADHD}$ is one of a number of labels ascribed to situations in which women fail to attain to normative societal expectations of how they should behave and perform (Ussher 2010). According to this view, the adult ADHD concept represents an instance of the medicalization of normal behavioural variation, which is supported by the fact that all ADHD symptoms including, for example, failure to pay close attention to detail, being forgetful, and easily distracted and losing things are indeed universal experiences (Moncrieff et al. 2011). The diagnosis of ADHD may be understood therefore as a response to the particular demands that modern life places on women, consistent with Conrad and Potter's interpretation of adult ADHD as the "medicalization of underperformance" (Conrad \& Potter 2000). In this manner the diagnosis locates the gender-specific problems generated by current social and political structures as a property of the brains of individual women. The invisible parameters of social acceptability, which define and constrain women's behaviour, are reinforced by the 
pathologisation of deviations, which has traditionally lead to the over-representation of women among many mental health diagnoses (Ussher 2010).

The benefits associated with the "medicalisation of underperformance" illustrate why people might actively pursue an ADHD diagnosis. Such individuals can be characterised as "active consumers" of a biomedical orientation as opposed to the passive stance associated with the traditional patient role (Speed 2006). Evidence suggests that adult ADHD was initially promoted by self-identified sufferers utilising the popular media (Conrad \& Potter 2000).

The fact that women have traditionally been the largest consumers of prescribed psychotropic medication suggests they may be particularly inclined to adopt internalised, biological explanation of their situations. Over the last few years, marketing of ADHD medication has started to target women in particular, asserting, for example, that "too often ADHD women and girls go undiagnosed and untreated" and encouraging them to "learn how to recognise symptoms and get help" (Connolly 2010). This strategy clearly identifies a female-specific component to the diagnosis.

Despite the emergence of the female market for ADHD medications, there has been little research into the mechanics of how the ADHD adult has been constructed in the media and how this concept has been related to women.

It is in the context that we apply principles of discourse analysis to generate analytical insight into the gendering of ADHD diagnosis and what this might demonstrate about wider issues of gender and psycho-pathology. Following Foucault (1972), <AQ: Foucault is not listed in 
References $>$ discursive psychology seeks to examine the mechanisms through which knowledge is produced (see Potter \& Weatherall 1987; Parker 1992). Through micro-level analysis of talk and text, discourse analysis aims to uncover the way descriptions become "fact," and how these “facts" are employed to perform particular actions (Potter 1996).

We locate our discourse analytical frame within a broad feminist trajectory (Wilkinson \& Kitzinger 1995; Lazaar 2005). <AQ: Wilkinson \& Kitzinger 1995 is not in References>This enables us to take a critical stance towards psychiatric nosology in relation to ADHD (Kirschner 2013), <AQ: Kirschner is not in References $>$ whereby we can identify and problematise the normative, and often psychopathological constructions of gender in mainstream psychiatric diagnosis.

Following McHoul and Rapley (2005), we supplemented the framework and techniques of discursive psychology with principles of critical discourse analysis (CDA) (Fairclough 1995). Whereas conventional discourse analysis is primarily concerned with "how people use discursive resources in order to achieve interpersonal objectives in social interaction" (Willig 2001, p. 91, italics in original), critical discourse analysis aims to make transparent the relationships between discourse, social practices, and social structures (Fairclough 1992). In this sense, gender relations, in terms of notions of patriarchy, and how they position women within medical discourse to issues of patriarchal power and oppression (see Busfield 1988) are regarded as enduring social structures. $<\mathrm{AQ}$ : Busfield is not in References>

To demonstrate these processes, we utilise an analysis that identifies the range and role of rhetorical devices employed at a micro level to establish and communicate meaning. This focus 
on rhetoric takes a view that claims and descriptions in talk and text are "pervasively rhetorical" (Potter \& Edwards 2001). $<$ AQ: Potter \& Edwards is not in References $>$ That is to say, the claims and descriptions that people use are "often designed to counter potential alternative versions and resist attempts...to disqualify them as false, partial or interested" (p. 104). Drawing from previous research we identified a list of 20 rhetorical devices (see Table 1) that are utilised to bolster a gendered diagnosis of ADHD (via a set of discursive practices which we characterise as "medicalisation of underperformance") or, more negatively, to limit possible criticisms of this gendering of ADHD. <TQ: table 1 first mention>

\section{Methods}

In the present study, we used discourse analysis to explore the meaning of selected YouTube video clips about ADHD in women.

The Internet is now seen as fundamental in helping to deliver messages, sell products, and promote action, making it a valuable source for analysis (Conrad \& Potter 2000; Norris \& Lloyd 2000). We selected a corpus of data from the online video search engine YouTube (www.youtube.com), which gains more than 800 million new users each month, with over 1 trillion views in 2011 (YouTube 2012).

We conducted searches using the term "ADHD Women," repeating the process seven times over the census period of September 2011-July 2012. We then collated the seven most commonly featured videos from all seven searches. The number of searches and videos was determined 
partly by a judgement about saturation of the data, and partly by external constraints on time and resources.

The videos were transcribed using the Jefferson Lite protocol (Parker 2005), and the content was categorised initially in line with the phases proposed by Potter and Wetherall (1987).<AQ: Wetherall is not in References> Phase 1 centred on the identification of "systemic patterns" of use of discursive devices, and phase 2 focused on a search for "functional effects and consequences," in other words the attitudes and actions the language was intended to promote (Tuffin \& Howard 2001, p. 203). Phase 2 led to the identification of overarching categories with which to organise the data. These were allowed as far as possible to materialise from the text through numerous readings and re-readings, whilst also attending to the themes, concepts, and embedded power relations (Fairclough 1992).

The analysis of rhetorical strategies proceeded by allocating episodes of text or talk to types of rhetorical device with an explicit focus on identifying the linguistic work that was being done by framing talk within specific rhetorical frameworks. One example is category entitlement $<\mathrm{AQ}$ : Okay to delete superscript 2 ? $>$ where talk is constructed as originating from a creditable or knowledgeable position relevant to the claim being made. In the third video, for example, the reporter on the news item comments that "doctors say this [medication] is the best form of treatment," illustrating how a claim is reinforced by association with a professional point of view.

To ensure the reliability of the analysis, the first author maintained a reflexive diary, engaged in ongoing conversations with colleagues, and discussed the analysis during regular meetings of the 
Loughborough Discourse and Rhetoric Group (DARG). A section of one of the videos and its accompanying analysis was presented to members of DARG for feedback.

Our analysis considered video materials available over the Internet. We did not analyse the visual representations offered; rather we took the talk contained within these clips and transcribed it to offer us a set of texts that we could analyse. We were not analytically interested in the visual representations, but rather in the rhetorical devices utilised within their talk.

All the data was publicly accessible but names have been changed for the purpose of the present analysis.

Results

The extracts analysed in this paper represent a combination of first-person testimony from people who identify themselves as "sufferers" of ADHD, and the sharing of "expertise" by "professionals." Further information about each of the videos used in this analysis may be found in Table 2.<TQ: table 2 first mention $>$

All videos involved some commentary by, or interviews with, women identified as having ADHD. Three videos were personal video "blogs" made by women identifying themselves as ADHD sufferers and discussing their views on the effects of the condition, its nature and their experience of treatment (videos 1, 4, and 5). As such the common rhetorical device of category entitlement is employed in order to enhance the authority of the claim through the narrator's position as a person with assumed personal experience. All these videos presented the case that receiving the diagnosis and treatment of ADHD has been beneficial. 
The narrator of one of these videos (video 5) is referred to in the video's introduction as "Dr," and introduced as "PhD, an ADHD expert and author of four books." The nature of her qualifications is not clarified, leaving the impression that she might be a medical doctor. This provides a further example of category entitlement, with the emphasis on the narrator's professional expertise and the association with medical authority. A link in the video to the personal website of the narrator reveals that she is trained as a counselor.

Video 5 was presented as having been made for ADDitude magazine, a magazine that receives sponsorship from the pharmaceutical industry. No pharmaceutical industry sponsorship was apparent for any of the other videos, but video 4 was associated with a site advertising an alternative medicine, "ADDTabz: The Adderall Alternative for Everyone."

Apart from the three video blogs, the other two videos consisted of a news report for the CBS News channel and a documentary made by a student for a university course. The news report included interviews with three sufferers and a medical expert. No experts critical of the concept of adult ADHD were interviewed, and the content, largely derived from the interviews, mirrored the themes in the personal video blogs. The documentary (video 2) was made by a self-identified ADHD sufferer, and although it included little of her own testimony, again the bulk of the video consisted of filmed interviews with women who considered themselves to have ADHD and a brief interview with a medical expert proponent of the ADHD diagnosis. As such, the content of this video also aligned with the material contained in the personal blogs of sufferers.

Content of the clips was organised according to four broad themes: 1) "ADHD is a 'real' biomedical disorder," 2) "fulfilling expectations," 3) "the right to be diagnosed," and 4) 
“increase your potential." We present selected extracts from these categories, which were selected because they exemplify the themes and allowed us to explore the strategies employed to construct the ADHD concept and the role of drug treatment in women.

\section{Theme 1: ADHD is a "real" biomedical disorder}

Each video presented ADHD as an uncontested, "real" medical disorder, as exemplified by Ashley, the narrator of video 1 . The analysis considered the ways in which the narrator's talk functioned to invoke the real, material basis of ADHD.

Extract 1 ADD is real. And some people treat it like it's some magic thing that's never been studied or proven before. It's pretty simple to run a test to see if there's physical proof of the malfunctioning of chemicals in your brain. And it's also pretty simple to take a pill that corrects those imbalances. Video 1: Ashley

Ashley's statement can be read as a direct response to the contested nature of ADHD; to the idea that its existence as a medical disorder is not "proven." Here (as in other clips) there is no direct engagement with, or response to, critiques of the concept. The rhetoric functions to create ADHD as a legitimate category whilst simultaneously refusing to acknowledge it is contested. Boyle (2002)<AQ: Boyle is not in References>, in her analysis of the construction of schizophrenia, states that one of the most successful ways to transform a social construct into a medical disorder is merely to state that it exists. The rhetorical device of assertion is evidenced in the statement "ADD is real" (extract 1, line 1). The extract also demonstrates the process of reification, in which the "real" (or "material") nature of ADHD is contrasted to the possibility of 
it being only a "magic," abstract or unreal entity. These two devices combined function as form of offensive rhetoric, that is, as claims that work to undermine alternative accounts of the phenomenon in question.

Ashley supports her position by citing "physical proof" that ADHD is caused by a "malfunctioning of chemicals" (lines 3-4) in the brain, and additional claims that drug treatment "corrects those imbalances" (line 5). This notion of the "chemical imbalance" has been described as encapsulating popular "lay and professional conceptions of the mechanism of mental illness" (Cohen \& Hughs 2008, p. 176)<AQ: Cohen \& Hughs is not in References $>$ and has been widely disseminated via pharmaceutical company websites and self-help literature (Johnson 2008, p. 147). <AQ: Johnson is not in References>

Assertions about chemical imbalances function more as legitimation devices for pharmaceutical treatment than as accurate reflections of scientific research findings (Lacasse \& Leo 2005). This type of talk uses neuroscientific vocabulary to construct an empiricist discourse associated with the technique of systemic vagueness. These devices function to add scientific plausibility to claims whilst remaining vague enough to obscure inconsistencies and divert attention from the speaker's stake.

Neuroscientific vocabulary is employed further by Ashley in the course of extracts 2 and 3.

Extract 2 Ok, my doctor explained it like this: it's like the chemical that makes us satisfied with whatever we're doing is produced $\underline{\mathrm{w}: \text { :ay }}$ less in my brain and that causes me to want to move on to something different every 2 minutes coz I'm never satisfied with what I'm doing. 
Extract 3Now this is important; if you take ADD medication; Adderrall, Ritalin, Concerta and you don't have ADD, your brain tries to correct an imbalance that isn't there.

Effectively giving you ADD. Ok a friend of mine explained it this way: Alright, now the solid line is a normal brain wave, the dotted line is a particular brain wave that is known as "out of phase." It's a rebellious, delinquent brain wave. It doesn't sit with the other brainwaves correctly and that's the problem. ADD medication shifts those particular waves back into phase. Now if someone's brainwaves are perfectly in phase, and they take ADD medication, it pushes them out of phase. This is why it has an opposite effect in people without ADD.

Video 1: Ashley

These extracts illustrate further use of systematic vagueness, providing a vague global formulation, with sufficient information to establish a statement, but insufficient detail to enable an effective challenge, such as what brain chemicals are thought to be involved or what exactly is meant by a "brain wave." In this extract, the chemical imbalance discourse combines empiricist discourse, claims of corroboration and consensus (between the empirical discourse and sufferer testimony), visual reinforcement through the use of the graph, and the category entitlement of sufferer testimony to effectively construct a strong case. Furthermore, Ashley can also be seen to use active voicing in the reporting of her friend's account of the chemical imbalance mechanism.

Ashley's explanations firmly position drug treatment for ADHD as a medical treatment targeted at reversing an underlying abnormality or disease. There is a conspicuous absence of reference to the well-recognised arousal-enhancing effects of stimulant drugs. 
Ashley's rhetoric works to legitimise the category of ADHD and to deflect contestation. Extracts 4 and 5 also employ rhetorical devices to shut off criticism, while implicitly revealing the contested nature of the condition.

Extract 4 Teresa: If I was in a wheelchair you could see, I had a disability, but, because it's hidden (.) no one understands.

Video 2: ADHD Myth or Reality P1

Extract 5 Kirsten: It is painful when people say to you: “oh you don't have

anything wrong with you." They wouldn't judge whether I had a heart condition or not. It's an invisible disorder.

Video 3: CBS News

These extracts demonstrate argument by analogy, invoking a congruence between ADHD and physical illness or disability. Drawing on principles that are taken to be beyond doubt, they illustrate the technique of rhetorical self-sufficiency. Since one would not question a person's condition if it was visual and/or physical, then by analogy, neither can ADHD be questioned. The power of the rhetorical analogy helps to shift ADHD into the physical health domain, bringing with it many taken-for-granted assumptions. Common-sense understandings of what it means to be physically ill or disabled, such as not having agency and therefore being beyond moral judgment, become embedded within what it means to "have ADHD." It thus becomes difficult to question ADHD given its ascribed material existence, as querying the diagnosis is 
equated with disavowing disability, or with inflicting "pain," being "judgemental" (extract 5, lines $1 \& 2$ ), and not "understanding" (extract 4, line 2).

\section{Theme 2: "Fulfilling expectations"}

\section{Extract: 6Beverly: I, I, I really really feel that if I got a diagnosis and coaching,}

like, to manage me ADHD, that I'd be so much better. Video 2: ADHD Myth or Reality

A dominant construction across all of the videos is that of the aspirational and life-improving qualities of ADHD diagnosis and treatment. Women in these videos are either happily diagnosed or seeking diagnosis, as if it were a consumer item (extract 6). To support this construction the rhetorical device of contrast is frequently used (verbal and visual) to favourably compare a life with diagnosis to a life without.

Extract: 7Reporter: Evelyn Pope Green went to College on a scholarship but once there she couldn't keep up, and she dropped out.

Evelyn: $\quad$ I can remember sitting in my apartment for days at a time in the dark, because once I fell behind, I didn't know how to catch back up. I didn't know what to do, erm, to fix it.

Reporter: Kirsten Boncher found daily life overwhelming: 
Kirsten: It's every little task that you have to do in a day; making breakfast, making lunch, making dinner and you see something else that you have to do so then you do that to.

Reporter: Does the stuff somehow not get done, or does it get done?

Kirsten: $\quad$ Erm, it gets done but it's, it's such agony.

Reporter: And with the agony, comes a feeling of failure. Lisa Wright couldn't seem, to finish anything:

Lisa: It's like having $99 \%$ done and I can't get the last step.

Reporter: Did it leave you with a lot of self-esteem issues?

Lisa: Yeh, mhmm, absolutely. Because I wanted to live up to be (.) what, what I thought I could be or what other people are,y'know. Video 3: CBS News

Dropping out of college, falling behind with household chores, and struggling to "finish anything" all serve as indexes of the extremity of the problems these women suffered as a result of not having been diagnosed and treated. Three-part lists are employed (making breakfast, making lunch, making dinner) to reinforce the overwhelming nature of daily life and vivid descriptions, such as "sitting in my apartment for days at a time in the dark," supply details to make the account authoritative and memorable. The use of three separate but similar cases creates corroboration and consensus across the women. The reporter weaves together the women's stories to create a depiction of life before the ADHD diagnosis and treatment as 
deficient and disappointing. Hence, despite all their efforts these women could not achieve in the ways they wanted, and experienced "such agony" (line 11) in trying. The action packaged within the descriptions is therefore a drive to "fix it" (line 5), which opens the metaphorical door to the potential that a diagnosis of ADHD offers these women, as described in extract 8 .

\section{Extract: 8}

Reporter: Today, with the right diagnosis and treatment all three women are doing well; Kirsten can now enjoy her family more, Lisa started her own business and Evelyn is a school administrator in Chicago. It's not always easy, but that's ok.

Video 3: CBS News

Here we see an explicit example of the "medicalisation of underperformance" (Conrad \& Potter 2000). The three women depicted in the video are faced with a binary choice between obtaining a diagnosis and treatment and living "happily ever after," or remaining undiagnosed and living a life of hardship and failure.

The three-part list of extract 8 functions to offer corroboration and consensus regarding the utility of the label and consequent treatment, demonstrating the ways these women's lives have changed for the better. The rhetorical work of this section is complemented and reinforced by three accompanying images. One shows a woman calmly reading with her two children, and the other two show women working surrounded by papers and computers. The images and narration reflect Western values in relation to both family and career success. Diagnosed and medicated, 
these women are now capable of working hard to achieve the possibility of prosperity and upward social mobility; "all three women are doing well" (lines 1-2).

\section{Theme 3: The right to be diagnosed}

Many of the videos sampled describe the process of getting an ADHD diagnosis as a struggle with "many who are still fighting for it" (Constanze, Video 2, part 2). Women describe the process of trying to persuade clinicians that they have the diagnosis, and in Video 2 Teresa, from the United Kingdom, suggests the possibility of obtaining the diagnosis by "going private."

Extract 9Teresa: $\quad$ So I've, I've wanted to try and get a diagnosis but I've found it really really hard.... The only way for me to get diagnosed is either to go private, which, I will do; I'll be going to the Priory in Manchester. But at the moment I can't do that because me life is so busy with me own son, but eventually I will, try and get that diagnosis and I know I will, if I go private I will $>$ get it.

Video 2: ADHD Myth or Reality Pt1

In this extract we can see Teresa using repetition of "hard" and "I will" both to reinforce her determination to obtain the ADHD diagnosis, and as an appeal to pathos; a rhetorical device used to appeal to the audience's emotions. Mention of her son functions to establish the character of the speaker as a "good mother," an appeal to ethos, signalling the honesty and authority of Teresa, as well as to pathos (Howard 2010). $<$ AQ: Howard 2000 is not in References $>$ Teresa's intention to wait to obtain her diagnosis privately illustrates how ADHD diagnosis and treatment, like other consumer goods, have become something to save up for and invest in. Her choice of 
the Priory helps add weight to her cause, since the Priory Group holds an elite status due to its celebrity clientele, (e.g., Kate Moss and Amy Winehouse) (Moya 2010).<AQ: Moya is not listed in References>

\section{Theme 4: "Increase your potential"}

The following extracts emphasise the need for drug treatment within a biomedical framework, but they also illustrate the difficulty of distinguishing the treatment of underperformance or dysfunction from the enhancement of normal performance. In video 4, Luciana talks with energy and enthusiasm about the positive effects of the stimulant drug Adderall (amphetamine).

Extract: 10And, today I'm gonna talk about Attention Deficit Disorder, because I definitely have it. And, I finally got medicated, which is something that has really changed my life. And has, erm, been very positive for my business.Video 4: Luciana

Luciana begins by asserting the existence of ADHD in its reified form; "I definitely have it" (line 2) (Potter 1996). Medication is consequently promoted as "life-changing" and "positive for business." These descriptions draw on the rhetoric of extreme case formulations, which are designed to be dramatic and persuasive by constructing an outcome as significantly different from normative expectations. The identification of a positive impact from the diagnosis speaks directly against the stigmatisation of so many psychiatric diagnoses.

In Extract 11, Luciana uses the rhetorical device of active voicing to present the views and impressions of her colleagues as corroborating her depiction of the difficulties she faced premedication. This also creates a shift in footing as Luciana becomes merely the reporter of her 
employee's opinions, which helpfully corroborate her own story. Luciana also explicitly connects her increased "potential" with being medicated:

Extract: 11 "hey, you know, Luciana, you need to get some ADD medicine, because you can't focus on what you want us to do, and, y-you have a hundred things going at the same time, and em, you can't, err, channel all your energy so...”

I feel like my potential has sky-rocketed now that, erm, I'm on medication.

\section{Video 4: Luciana}

Luciana constructs her difficulties within the dominant biomedical discourse providing a narrative of abnormality. The rhetorical device of a narrative form of accounting can also be seen to be at work here, helping to increase the plausibility of an account (Harper 2004). Luciana's argument runs thus

I have ADD > I had difficulty focussing and channelling energy $>$ employees noticed $>$ I finally got medicated $>$ medication changed my life

Although the video suggests the use of prescribed, conventional medication, it is in fact associated with a site marketing an alternative medicine. It is interesting to note that the theme of performance enhancement through medication is still the principal message.

In Extract 12 the narrator, who identifies herself as a doctor, speaks about the positive impact the medication has had on her home life. Since this video was associated with an Internet magazine 
sponsored by the pharmaceutical industry, it seems safe to conclude it refers to prescription stimulants and associated drugs for ADHD.

Extract 12Erm, I also noticed that, if I cook, coz I love to cook, I can actually clean the kitchen afterwards, which has been, like monumental, because I cook and I just like leave it because, y'know I don't like to do all the detailed work. Erm, also I can read through something all the way through the first time and know what it says. And before I would read a paragraph, have to go back and read it again, because by the time I got to the end of the page I was like what did I just read. So medication's really helped in those aspects of life.

\section{Vidoe 5: Dr Walker}

Dr. Walker again uses contrast to highlight her transformation with the help of ADHD medication. The examples she chooses, by their ubiquity, effectively democratise access to the ADHD label; needing to re-read paragraphs as one's mind has wandered (line 8); feeling reluctant to clean up the kitchen after cooking (line 4); each example, demonstrating how ADHD medication can provide a remedy "in those aspects of life" (line 9). Indeed, in the "comments" section of this video one user writes: "the dishes! OH MY GOD! it's always the dishes!" [sic] to which Dr. Walker responds

"Thave to unload and load the dishwasher today, and I have done everything else on my 'to do' list except that. lol Maybe 'dishwasher dysfunction' should be added to the DSM diagnostic criteria for ADHD. :)” $</ E X T$ ? 
Despite the emphasis on the performance-enhancing qualities of ADHD drug treatment, by omitting any reference to the drugs' mind-altering properties, these extracts concur with the view expressed earlier by Ashley that drugs work as a disease-targeting treatment rather than a chemical stimulant. However, Ashley herself in Extract 13 demonstrates how the drugs may be employed for increasing short-term mental endurance and performance.

\section{Extract 13}

And I only take it on days that are very academically demanding. Because there are side effects and they're not fun.Video 1, Ashley

In contrast to the biomedical model espoused by Ashley earlier, in which drug treatment is justified because it reverses an underlying pathology, Ashley takes medication only in situations in which she feels its immediate effects will be beneficial and outweigh its negative effects. In this view, the drugs are a "means to an end" and she chooses when to take them in a consumerist manner, as one might choose to drink coffee to facilitate concentration, but avoid it at other times due to migraines. There are clear parallels here with recreational drug use, whereby the user is pursuing a "temporary but potent altered state of consciousness" (Page \& Singer 2010, p. 9).

\section{DISCUSSION}

It has been particularly remarkable to note that a diagnosis that was once almost entirely limited to boys (Timimi 2005) is now being readily applied to women. This article has highlighted some of the rhetorical tropes that are used to establish the gendered concept of the ADHD woman, and to illustrate the benefits of the diagnosis and treatment in helping to conquer the multiple demands and responsibilities of the modern-day "superwomen" (Wilkinson \& Kitzinger 1996). 
As such the analysis illustrates the commodification of certain problems into an ADHD "product" with a specific female identify, which is accomplished by reinforcing normative ideals of accepted female roles.

\section{ADHD as a biomedical condition}

It is not possible to provide a thorough critique of the evidence on whether ADHD can legitimately be identified as a discrete brain-based disorder, but it is worth highlighting a few points. First, the validity of childhood ADHD diagnosis has been contested (Timimi et al. 2004), and it is generally agreed that adult ADHD is a weaker, less reliable, and more contested concept (Moncrieff \& Timimi 2010). Second, research on brain characteristics such as dopamine levels and brain structure does not differentiate children or adults diagnosed with the condition from those without (Del Campo et al. 2013), and is confounded by uncontrolled factors such as medication use (Leo \& Lacasse 2009). Third, despite popular views (as illustrated in extracts 2 and 3), stimulant medication has not been shown to have specific effects in people diagnosed with ADHD in comparison with people without the diagnosis, and animals (Arnsten 2006). Fourth, although stimulant drugs produce immediately detectable effects, including increased focus on repetitive tasks, long-term studies in children and adults show little difference between effects of ADHD medications and nonpharmacological treatments or a placebo (Jensen et al. 2007; Adler et al. 2008). Indeed, the National Institute for Health and Clinical Excellence (NICE) acknowledges the paucity of the evidence on the real-world benefits of drug treatment in children (NICE 2008). 
The videos presented highlight none of the uncertainties about, and debates over, the nature of ADHD and the efficacy of treatment. The fact that adult ADHD is a contentious concept can only be inferred from the need of the interlocutors to assert its existence so forcefully, and from the complaints of some about the condition not being seen to have parity with physical illness. The extracts illustrate how a concept can be established through assertive statement, use of empirical data, images and language, and through avoiding engaging in debates about its validity or the nature of the evidence.

\section{Being "superwoman"}

In line with the conception of adult ADHD as the "medicalization of underperformance," the ADHD "symptoms" portrayed in the videos consist of everyday difficulties that centre around lack of achievement. Women in the videos wanted to achieve more or felt that they should be able to achieve more than they did. The experiences they described are familiar to all women to some degree, and as such, the videos express the general insecurities of modern women, facing the dual expectations of having a successful career and managing a home.

Obtaining an ADHD diagnosis and treatment was portrayed as transformative, enabling women to live more productive lives at work and at home. Although couched in the language of disease, the videos present ADHD and its treatment as a technique for performance enhancement, much like cosmetic surgery is promoted in relation to physical appearance. ADHD was offered as a diagnosis that women have a right to, that they should aspire to, and actively seek to maximise their potential. The sufferers portrayed in the videos behaved as "active consumers" of the biomedical discourse of ADHD, pitting themselves against scepticism, in a fight to assert their 
"right" to a diagnosis and drug treatment (Speed 2006). Our data therefore suggest that consumer activism, which led to the establishment of the concept of adult ADHD in the 1990s (Conrad \& Potter 2000), remains an important way in which the diagnosis is legitimised.

Other research indicates how the pharmaceutical industry has helped promote the concept of adult ADHD especially over the last decade, and how much promotional material focuses specifically on women (Moncrieff et al. 2011). Only one of the YouTube videos examined was linked to a pharmaceutical industry-sponsored organisation (ADDitude magazine), and one to a site marketing an alternative medicine. Nevertheless, the ideas conveyed in all the videos are aligned with those promoted by the makers of drugs and medicines, conventional or unconventional. As with other Internet material, YouTube videos provide a vehicle for the widespread delivery of messages that bypass restrictions on "direct-to-consumer" advertising that exist in most countries outside the United States. As such, the material presented here illustrates how consumer activism and corporate interests can coincide, each reinforcing the other (Light 2010).

In discussing "discourses of femininity," Stoppard (2000) described the way women continue to be judged against old ideas of what it is to be female (e.g., housewives) as well as now needing to be successful career-women and look eternally young and attractive. In this climate of burgeoning expectations for women to fit "uniform and unrealistic standards" in body and mind (O'Grady 2005, p. 33), it is not surprising that some women feel they are failing and that ADHD should prove an appealing lens through which they can understand and organise their lives. $<$ AQ: O'Grady is not in References> 
"Failing to finish household chores" appears in the DSM-5 as a symptom of adult ADHD (APA 2012, p. 1) and the videos explicitly promoted medication as a way overcoming such difficulties, as well as supporting academic and occupational success. In the United Kingdom, 69\% of working-age women are in paid employment (Office for National Statistics 2012) and 92\% still complete all the household tasks. Gill (2007) suggests that, for women, "carrying out a doubleday is rendered invisible by the superwoman imagery" (p. 97) of "having it all."

The idea that women diagnosed with ADHD, depression or anxiety are suffering from biomedical brain disorders "serves to divert attention away from the problems within society, focussing attention onto the individual, who is suffering only as a direct result of societal pressures" (Ussher 1991, p. 148). Similarly, although drug treatment was apparently being used to boost performance, the only explicit explanations of how drug treatment might work suggest a disease-targeting mechanism. The videos inevitably provide glimpses of the stimulant effects of the medication, but the notion that women might be using mind-altering drugs to ensure they demonstrate optimum performance in every area of their increasingly demanding lives is obscured by the medical framework in which treatment is presented.

Adult ADHD pathologises both underperformance and underproductivity (Conrad \& Potter 2000) and offers a solution in the form of stimulant drugs. In this way, the epidemic of adult ADHD diagnoses, and increasing levels of stimulant use (Ilyas \& Moncrieff 2012), can be perceived as consonant with the consumerist and competitive values of late capitalist society. Just as Martin suggested that bipolar disorder was the fashionable diagnosis of the economic boom because mania was regarded as being helpful to achieve ever greater levels of productivity 
(Martin 2009), the effects of stimulant treatment are presented as helping women to cope with increasingly pressurised lifestyles. By suggesting that individuals who are not performing at a certain level are compromised and require modification, the values of the economic system come to seem natural and universal, and become embedded in prevailing social ideas about "normal life."

\section{Conclusion}

ADHD is being offered to women by other women as a formulation of their "underperformance" and a key to the solution (Conrad \& Potter 2000). By dissecting the way women's experience is presented and revealing the assumptions and persuasive techniques embedded in these representations, these limiting "discourses of femininity" may be brought to the surface, deconstructed and challenged. Meanwhile, without a detailed and sustained critique of these and similar gendered categories of diagnosis, "mother's little helper" could be set to make a comeback!

Acknowledgements

The authors are grateful for the inspiration and support of Professor Mark Rapley, formerly of University of East London, who acted as the first supervisor for the research up until his untimely death in July 2012. 


\section{REFERENCES}

Adler, L, Spencer, J, Levine, L, Ramsey, J, Tamura, R, Kelsey, D, Ball, S, Allen, A \& Biederman, J 2008, 'Functional outcomes in the treatment of adults with ADHD', Journal of Attention Disorders, vol. 11, no. 6, pp. 720-7.

Arnsten, A 2006, 'Stimulants: therapeutic actions in ADHD', Neuropsychopharmacology, vol. 31, no. 11, pp. 2376-83.

American Psychiatric Association 2012, 'DSM-5 Development: 06 Attention Deficit/Hyperactivity Disorder', in Rationale for Changes in ADHD in DSM-5. Arlington, VA, <AQ: provide page number for chapter>viewed June 2012, http://www.dsm5.org/ProposedRevisions/Pages/proposedrevision.aspx?rid=383\#

Asherson, P 2013, 'ADHD in adults: a clinical concern', in C Surman (ed.), ADHD in adults, Humana Press, Boston.

Boyett, J 2008, Won't get fooled again, AMACOM, New York.

Bren, L 2004, 'ADHD: not just for kids anymore', FDA Consumer Magazine, vol. 38, no. 6.

Castle, L., Aubert, R., Verbrugge, R., \& Khalid, M. (2007). 'Trends in medication treatment for ADHD', Journal of Attention Disorders, vol. 10, no. 4, pp. 335-42.

Connolly, M 2010, 'ADD women and girls: late diagnosis, little treatment', ADDitude magazine. 
Conrad, P \& Potter, D 2000, 'From hyperactive children to ADHD adults: observations on the expansion of medical categories', Social Problems, vol. 47, no. 4, pp. 559-82.

Del Campo, N, Fryer, T, Hong, Y, Smith, R, Brichard, L, Acosta-Cabronero, J, Chamberlain, S, Tait, R., Izquierdo, D, Regenthal, R, Dowson, J, Suckling, J, Baron, J, Aigbirhio, F, Robbins, T, Sahakian, B \& Muller, U 2013, 'A positron emission tomography study of nigro-striatal dopaminergic mechanisms underlying attention: implications for ADHD and its treatment', Brain, vol. 136, no. 11, pp. 3252-70.

Dickerson, P 1997, “It's not just me who's saying this..." The deployment of cited others in television political discourse', British Journal of Social Psychology, vol. 36, pp. 33-48.

Edwards, D \& Potter, J 1992, Discursive psychology, Sage, London.

Fairclough, N 1992, Discourse and social change, Polity Press, Cambridge.

Getahun, D, Jacobsen, S, Fassett, M, Chen, W, Demissie, K \& Rhoads, G 2013, 'Recent trends in childhood attention-deficit/hyperactivity disorder', JAMA Pediatrics, vol. 167, no. 3, pp. 2828.Please confirm volume, issue, and page range for Getahun.

Gill, R 2007, Gender and the media, Polity Press, Cambridge.

Harper, D 2004, 'Storying policy: constructions of risk in proposals to reform UK mental health legislation', in B Hurwitz, T Greenhalgh, \& V Skultans (ed.), Narrative research in health and illness, Wiley-Blackwell, Sussex. 
Healy, D 2006, 'The latest mania: selling bipolar disorder', PLoS.Med., vol. 3, no. 4, p. e185.

Ilyas, S \& Moncrieff, J 2012, 'Trends in prescriptions and costs of drugs for mental disorders in England, 1998-2010', British Journal of Psychiatry vol. 200, no. 5, pp. 393-8.

Hepburn, A 2003, An introduction to critical social psychology, Sage, London.

Jensen, P, Arnold, L, Swanson, J, Vitiello, B, Abikoff, H, Greenhill, L, Hechtman, L, Hinshaw, S, Pelham, W, Wells, K, Conners, C, Elliott, G, Epstein, J, Hoza, B, March, J, Molina, B, Newcorn, J, Severe, J, Wigal, T, Gibbons, R \& Hur, K 2007, '3-year follow-up of the NIMH MTA study', Journal of American Academic Child and Adolescent Psychiatry, vol. 46, no. 8, pp. 989-1002.

Koerner, B 2002, 'Disorders made to order', Mother Jones, vol. 27 (July/August), pp. 5863.Please confirm year, volume, and page range for Koerner.

Lacasse, JR \& Leo, J 2005, 'Serotonin and depression: a disconnect between the advertisements and the scientific literature', PLOS Medicine, vol. 2, no. 12, p. e392. doi:10.1371/journal.pmed.0020392

Leo, J \& Lacasse, J 2009, 'The manipulation of data and attitudes about ADHD: A study of consumer advertisements', in S Timimi, \& J Leo (eds.), Rethinking ADHD: From brain to culture, Palgrave-Macmillan, Hampshire, pp. 287-312. 
Light, D 2010, 'Health-care professions, markets and countervailing powers', in C Bird, P Conrad, A Fremont, and S Timmermans (eds.), Handbook of medical sociology, Vanderbilt University Press, Nashville.Please confirm publisher city for Light.

Martin, E 2009, Bipolar expeditions: mania and depression in American culture, University Press, Princeton.

McHoul, A \& Rapley, M 2005, ‘A case of attention-deficit/hyperactivity diagnosis: Sir Karl and Francis B slug it out on the consulting room floor', Discourse and Society, vol. 16, no. 3, pp. 419-49.

McKay, T 2000, Guidelines for critical thinking: reasons, explanations and decisions, Wadsworth, Belmont, CA.Please confirm publisher city for McKay.

Moncrieff, J, Rapley, M \& Timimi, S 2011, 'The construction of psychiatric diagnoses: the case of adult ADHD', Journal of Critical Psychology Counselling and Psychotherapy, vol. 11, no. 1, pp. 16-29.

Moncrieff, J \& Timimi, S 2010, 'Is ADHD a valid diagnosis in adults? No', $B M J$, vol. 340, p. c547.

National Institute for Health and Clinical Excellence 2008, Attention deficit hyperactivity disorder. Diagnosis and management of ADHD in children, young people and adults. National Clinical Practice Guideline Number 72, National Institute for Clinical Excellence, London. 
Norris, C \& Lloyd, G 2000, 'Parents, professionals and ADHD: what the papers say', European Journal of Special Needs Education, vol. 15, no. 22, pp. 123-37.

Office for National Statistics 2012, Labour market statistics, Her Majesty's Stationery Office, London.

Page, B \& Singer, M 2010, Comprehending drug use: ethnographic research at the social margins, Rutgers University Press, New Brunswick, NJ.

Parker, I 1992, Discourse dynamics: critical analysis for social and individual psychology, Routledge, London.

Parker, I 2005, Qualitative psychology: introducing radical research, Open University Press, Maidenhead.

Pomerantz, A 1986, 'Extreme case formulations: a new way of legitimating claims', Human Studies, vol. 9, pp. 219-30.

Potter, J 1996, Representing reality: Discourse, rhetoric and social construction, Sage, London.

Potter, J \& Wetherell, M 1987, Discourse and social psychology, Sage, London.

Simon, V, Czobor, P, Balint, S \& Meszaros, A 2009, 'Prevalence and correlates of adult attention-deficit hyperactivity disorder: meta-analysis', British Journal of Psychiatry, vol. 194, pp. $205-11$. 
Speed, E 2006, 'Patients, consumers and survivors: a case study of mental health service user discourses', Social Science and Medicine, vol. 62, no. 1, pp. 28-38.

Stoppard, J 2000, Understanding depression: feminist social constructionist approaches, Routledge, London.

Timimi, S 2005, Naughty boys: antisocial behaviour, ADHD and the role of culture, Palgrave Macmillan, Hampshire.

Timimi, S \& Leo, J 2009, Rethinking ADHD: from brain to culture, Palgrave Macmillan, Hampshire.

Timimi, S, Moncrieff, J, Jureidini, J, Leo, J, Cohen, D, Whitfield, C, Double, D, Bindman, J, Andrews, H, Asen, E, Bracken, P, Duncan, B, Dunlap, M, Albert, G, Green, M, Greening, T, Hill, J, Huws, R, Karon, B, Kean, B, McCubbin, M, Miatra, B, Mosher, L, Parry, S, DuBose, RS, Riccio, D, Shulman, R, Stolzer, J, Thomas, P, Vimpani, G, Wadsworth, A, Walker, D, Wetzel, N \& White, R 2004, 'A critique of the international consensus statement on ADHD', Clinical Child and Family Psychology Review, vol. 7, no. 1, pp. 59-63.

Tuffin, K \& Howard, C 2001, 'Demystifying discourse analysis', in A McHoul \& M Rapley (eds.), How to analyse talk in institutional settings: a casebook of methods, Continuum, London, pp. 196-205.

Ussher, J 1991, Women's madness: misogyny or mental illness, Harvester Wheatsheaf, Hertfordshire. 
Ussher, J 2010, ‘Are we medicalizing women's misery? A critical review of women's higher rates of reported depression', Feminism Psychology, vol. 20, pp. 9-35.

Wilkinson, S \& Kitzinger, C 1996, Women and health: feminist perspectives, Taylor \& Francis, London.

Willig, C 2001, Introducing qualitative research in psychology: Adventures in theory and method. Open University Press, Buckingham.

Wooffitt, R 2005, Conversation analysis and discourse analysis: A comparative and critical introduction, Sage, London.

YouTube 2012, YouTube: Press Statistics, viewed 31 July 2012, http://www.youtube.com/t/press_statistics 
Table 1

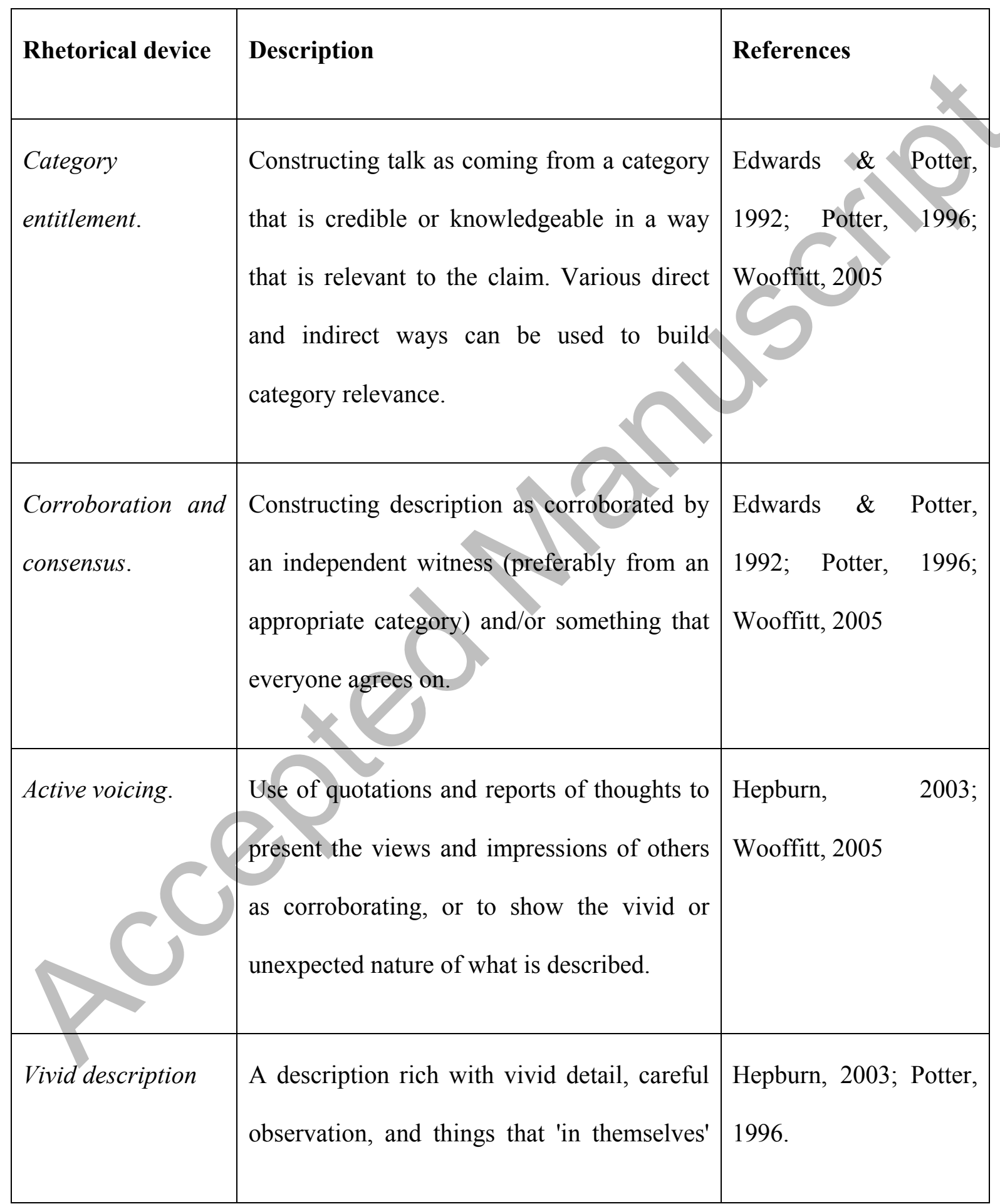




\begin{tabular}{|c|c|c|}
\hline & $\begin{array}{l}\text { would not be surprising, invoking the } \\
\text { powerful category: witness }\end{array}$ & \\
\hline $\begin{array}{l}\text { Systematic } \\
\text { vagueness. }\end{array}$ & $\begin{array}{l}\text { Being systematically vague about features of } \\
\text { descriptions that may be inconsistent or } \\
\text { debatable or which draw attention to the } \\
\text { speakers stake and interest in the claims they } \\
\text { are making }\end{array}$ & $\begin{array}{l}\text { Edwards \& Potter, } \\
1992\end{array}$ \\
\hline Three-part lists & $\begin{array}{l}\text { Used to construct something as normal or } \\
\text { standard and for emphasis }\end{array}$ & Jefferson, 1990 \\
\hline Contrast & $\begin{array}{l}\text { Use of contrast to highlight difference } \\
\text { between two states or situations }\end{array}$ & Boyett, 2008 \\
\hline Assertion & Statement of a 'fact' as if proven and beyond & Boyle, 2002 \\
\hline 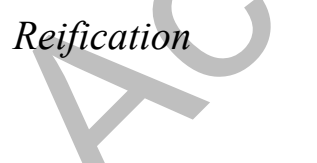 & $\begin{array}{l}\text { Talking of an abstract entity as if it were a } \\
\text { material thing }\end{array}$ & Potter, 1996 \\
\hline Offensive rhetoric & A statement designed to undermine & Potter, 1996 \\
\hline
\end{tabular}




\begin{tabular}{|c|c|c|}
\hline & alternative accounts & \\
\hline $\begin{array}{l}\text { Argument by } \\
\text { analogy }\end{array}$ & $\begin{array}{l}\text { Demonstration and persuasion through } \\
\text { analogy }\end{array}$ & $\begin{array}{l}\text { McKinlay\&McVittie, } \\
\text { 2008; }\end{array}$ \\
\hline $\begin{array}{l}\text { Rhetorical self- } \\
\text { sufficiency }\end{array}$ & $\begin{array}{l}\text { Referring to principles thought to be beyond } \\
\text { question }\end{array}$ & Wetherall\& \\
\hline $\begin{array}{l}\text { Empiricist } \\
\text { discourse }\end{array}$ & $\begin{array}{l}\text { Use of scientific-type language and data to } \\
\text { add plausibility to claims }\end{array}$ & Gilbert \&Mulkay, 1984 \\
\hline Active voicing & $\begin{array}{l}\text { Use quotations and reports of thoughts to } \\
\text { present the views and impressions of others } \\
\text { as corroborating, or to show the vivid or } \\
\text { unexpected nature of what is described. }\end{array}$ & $\begin{array}{l}\text { Hepburn, 2003; } \\
\text { Wooffitt, } 2005\end{array}$ \\
\hline $\begin{array}{l}\text { Visual } \\
\text { reinforce }\end{array}$ & $\begin{array}{l}\text { Use of images to reinforce claims or } \\
\text { arguments }\end{array}$ & $\begin{array}{l}\text { Campbell and } \\
\text { Huxmann, } 2009\end{array}$ \\
\hline $\begin{array}{l}\text { Action packaged } \\
\text { within } \\
\text { description }\end{array}$ & $\begin{array}{l}\text { Embedding an evaluation within a } \\
\text { description of events }\end{array}$ & $\begin{array}{l}\text { Edwards \& Potter, } \\
\text { 1992; Potter, } 1996\end{array}$ \\
\hline
\end{tabular}




\begin{tabular}{|c|c|c|}
\hline $\begin{array}{l}\text { Rhetoric of } \\
\text { argument }\end{array}$ & $\begin{array}{l}\text { Use of the logical argument form to justify } \\
\text { conclusions }\end{array}$ & McKay, 1999 \\
\hline Binary choice & Use of binary choice to set up a contrast & $\begin{array}{l}\text { Accepted linguistic } \\
\text { device }\end{array}$ \\
\hline $\begin{array}{l}\text { Epizeuxis/appeal to } \\
\text { pathos }\end{array}$ & Use of language to arouse empathy & Howard, 2010 \\
\hline Appeal to ethos & $\begin{array}{l}\text { Use of language to inspire respect for the } \\
\text { moral integrity of the speaker }\end{array}$ & Howard, 2010 \\
\hline Repetition & Use of repetition for dramatic effect & $\begin{array}{l}\text { Accepted linguistic } \\
\text { device }\end{array}$ \\
\hline $\begin{array}{l}\text { Extreme case } \\
\text { formulations }\end{array}$ & $\begin{array}{l}\text { Use these to strengthen arguments or display } \\
\text { investment in the arguments. }\end{array}$ & $\begin{array}{l}\text { Pomerantz, 1986; } \\
\text { Edwards, } 2000\end{array}$ \\
\hline Shifts in footing & $\begin{array}{l}\text { Changing the perspective e.g. quoting } \\
\text { people, or presenting yourself as merely a } \\
\text { reporter of another's views. This is closely }\end{array}$ & $\begin{array}{l}\text { Potter, 1996; } \\
\text { Dickerson, } 1997\end{array}$ \\
\hline
\end{tabular}




\begin{tabular}{|l|l|l|}
\hline & bound up with active voicing. & \\
\hline Narrative form of & Linking together of events into a sequence, & Potter, 1996; Harper, \\
accounting & $\begin{array}{l}\text { in a way that implies causality and increases } \\
\text { the plausibility of an account }\end{array}$ & 2004 \\
\hline
\end{tabular}


Table 2

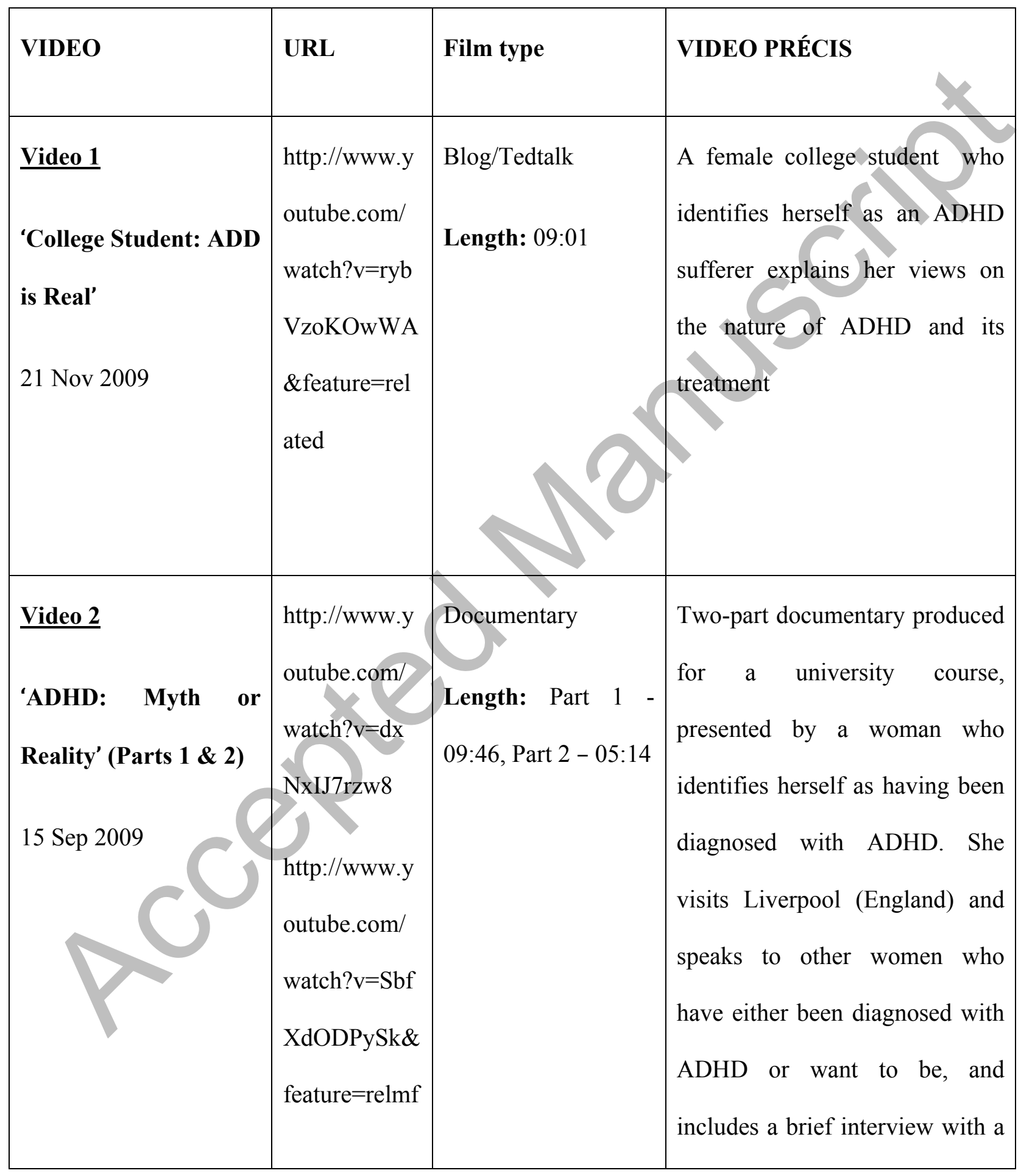




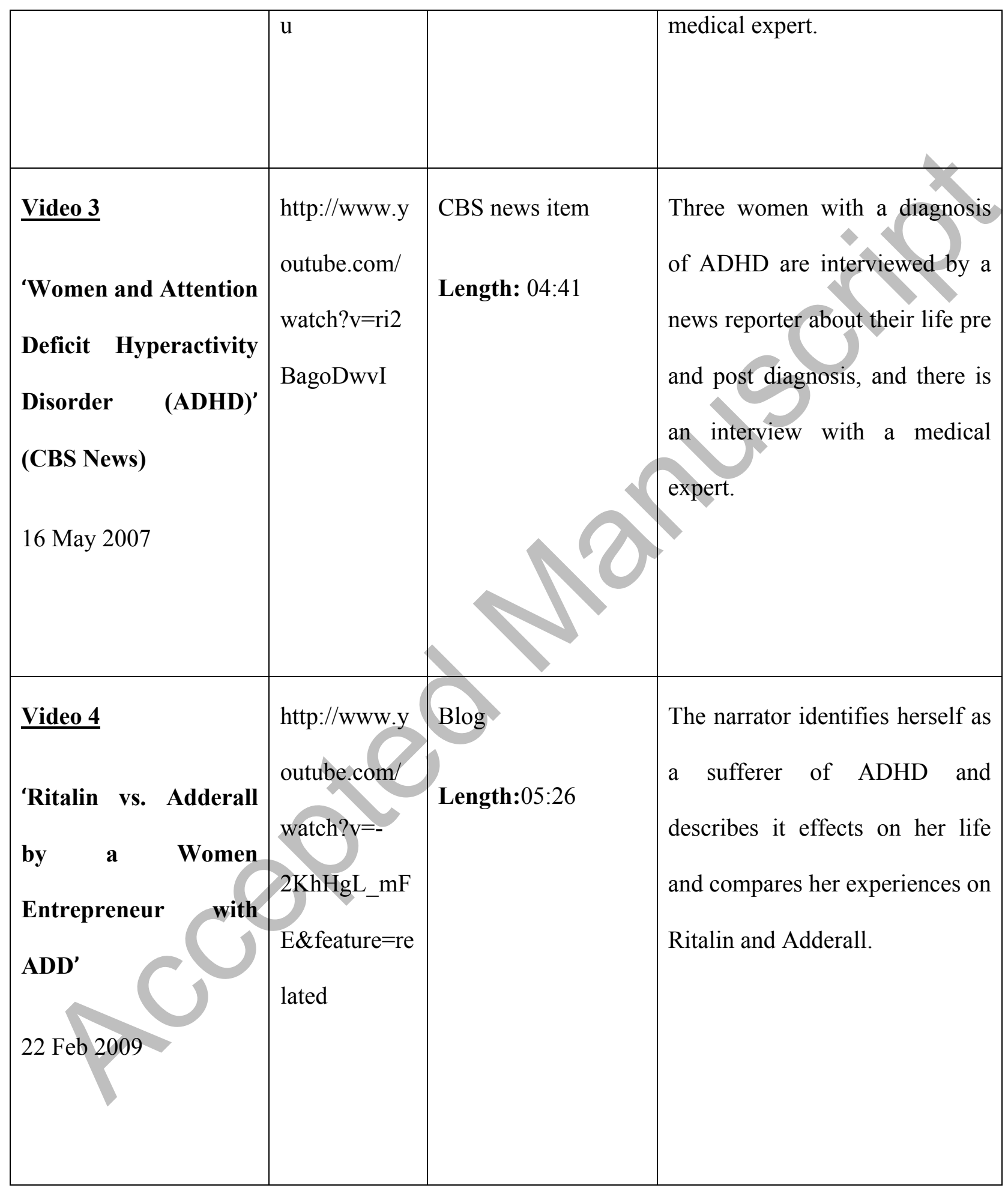




\begin{tabular}{|l|l|l|l|}
\hline Video 5 & http://www.y & Video blog made for & The narrator, who is presented as \\
'Dr Walker: My Life & outube.com/ & ADDitude magazine & a doctor, describes her own story \\
with ADHD' & watch?v=X4 & Length: 02:38 & of how she was diagnosed with \\
KG9utB2A & \&feature=rel & ADHD, its impact on her life \\
Published by: & ated & and the positive effects of \\
DocADHD, & & Adderall. \\
\hline 8 Jul 2008 & &
\end{tabular}

